\title{
EDUCAÇÃO FÍSICA, FORMAÇÃO DE PROFESSORES E EDUCAÇÃO A DISTÂNCIA (EAD): INVESTIGANDO A PRODUÇÃO DO CONHECI- MENTO NO ÂMBITO DAS CIÊNCIAS DO ESPORTE
}

\author{
Juliano Silveira \\ Universidade Federal de Santa Catarina, Florianópolis, Santa Catarina, Brasil \\ Giovani de Lorenzi Pires \\ Universidade Federal de Santa Catarina, Florianópolis, Santa Catarina, Brasil
}

\begin{abstract}
Resumo
O objetivo da presente pesquisa é contribuir para as discussões acerca da formação de professores de Educação Física na modalidade a distância (EAD), identificando como o tema vem sendo abordado nas principais produções acadêmicas da área. Para tal, apresenta um levantamento com base nos principais periódicos da área de Educação Física/Ciências do Esporte, no Banco de Dissertações e Teses da Capes e nos Anais do Congresso Brasileiro de Ciências do Esporte. A partir da identificação das temáticas específicas relacionadas à EAD. É apontado um possível "estado da arte" sobre o tema investigado, assim como lacunas a serem preenchidas por investigações futuras que tenham como foco as relações entre Educação Física e EAD.
\end{abstract}

Palavras-chave: Educação Física. Formação de Professores. Educação a Distância.

\section{Introdução}

A Educação a distância tem se constituído na contemporaneidade em um campo em pleno processo de expansão, tanto quando voltamos o olhar para a iniciativa privada, que parece ter reconhecido a mesma como um setor bastante lucrativo, como no setor público, concretizada principalmente como política governamental voltada para o desenvolvimento da educação e a formação de professores por todo o país.

Do ponto de vista legal, no Brasil, a partir de meados dos anos 90, a promulgação da LDB (Lei 9.394/96) ${ }^{1}$ estabeleceu um marco para a EAD reconhecendo-a como ferramenta para o desenvolvimento da educação em todas as modalidades de ensino. De acordo com o Art. 80, "o Poder Público incentivará o desenvolvimento e a veiculação de programas de ensino à distância, em todos os níveis e modalidades de ensino, e de educação continuada" (BRASIL, 1996, p. 43).

Outro documento de suma importância para o desenvolvimento da formação de professores via EAD foi o Plano Nacional de Educação (2001-2010) que, em seu item 11, que trata dos Objetivos e Metas da Educação Nacional destaca a importância de: "Iniciar, logo após a aprovação do Plano, a oferta de cursos à distância, em nível superior, especialmente na área de formação de professores para a educação básica” (BRASIL, Lei nº 10.172, 2001).

\footnotetext{
${ }^{1}$ Neste ano também foi criada a Secretaria de Educação a Distância (SEAD/MEC - Brasil. Decreto n ${ }^{\circ}$ 1.917, 1996).
} 
O decreto $\mathrm{n}^{\mathrm{o}} 5.622$ de 19 de dezembro de 2005 procurou ampliar a abrangência da EAD para todos os níveis de ensino, assim como delimitar o conceito de EAD. Em seu Art. $1^{\circ}$, afirma que

caracteriza-se a educação a distância como modalidade educacional na qual a mediação didático-pedagógica nos processos de ensino e aprendizagem ocorre com a utilização de meios e tecnologias de informação e comunicação, com estudantes e professores desenvolvendo atividades educativas em lugares e tempos diversos (BRASIL, 2005).

Um fato de extrema relevância no que tange a formação de professores no Brasil na modalidade à distância foi a criação do Programa Universidade Aberta do Brasil (UAB) ${ }^{2}$. Este Programa compreende um sistema integrado por universidades públicas que oferece formação superior para a camada da população que tem dificuldade de acesso à universidade, estando voltado, preferencialmente, para professores que atuam na educação pública básica sem titulação ou com titulação diversa da área de atuação (LISBOA; PIRES, 2013).

Face ao exposto, pode-se afirmar que a EAD emerge no contexto das políticas públicas em educação como possibilidade de ampliação do quadro de matrículas, "pela rápida expansão de vagas no ensino superior, uma vez que as limitações físicas e estruturais se tornam menos relevantes, já que grande parte do processo de ensino e aprendizagem ocorre em espaços escolhidos pelos alunos para desenvolverem seus cursos" (ARRUDA; ARRUDA, 2015, p. 322).

Sobre a citada expansão, de acordo com os dados do IBGE/PNAD (2014) ${ }^{3}$, enquanto as matrículas na educação superior presencial saltaram de três milhões em 2001 para mais de sete milhões em 2014, as matrículas no ensino superior na modalidade à distância saltaram de pouco mais de três mil em 2001 para cerca de 1,1 milhão em 2014, sendo quase 130 mil matrículas ofertadas por instituições públicas de ensino superior e as demais por instituições privadas.

Contudo, apesar da latente expansão e a penetração da EAD nos contextos educacionais convencionais, esta modalidade de ensino ainda enfrenta uma série de críticas, que tem levado os profissionais da educação a se defrontarem com implicações e desafios no que tange às práticas pedagógicas desenvolvidas na $\mathrm{EAD}$, a qualidade da formação docente proporcionada, os processos de precarização da força de trabalho empregada na realização dos cursos e o impacto de tais cursos sobre a educação nacional.

Para se ter uma ideia do peso de tais questionamentos sobre essa modalidade de ensino, recentemente, o documento final da Conferência Nacional de Educação/2010 (CONAE) apontou que

os cursos de formação inicial de professores não devem ocorrer na modalidade à distância, por conta do entendimento de que esses cursos não contemplam aspectos estruturais importantes da formação docente, como a relação mais próxima com a escola, e são soluções emergenciais questionáveis à demanda por mais professores nas escolas brasileiras (QUARANTA; PIRES, 2013, p. 52).

Apesar dessa ressalva, ainda assim, esta modalidade de ensino tem se constituído em um dos espaços destinados à formação de professores no Brasil, com um grande número de cursos de licenciaturas nas diversas áreas do conhecimento e, especificamente, na Educação Física no que tange à formação inicial e também a muitos outros cursos na esfera da formação

\footnotetext{
${ }^{2}$ A UAB foi instituída pelo Decreto 5.800/2006 e tem como meta "o desenvolvimento da modalidade de EAD com a finalidade de expandir e interiorizar a oferta de cursos e programas de educação superior no país".

${ }^{3}$ Citado por Arruda e Arruda, 2015.
} 
continuada. Compreender como a formação profissional em Educação Física tem sido investigada e discutida pela área de Educação Física/Ciências do Esporte constitui-se, assim, em tarefa de suma relevância para compreender-se esse fenômeno e avaliar seus êxitos e limitações.

Partindo desse pressuposto, a presente pesquisa tem como intuito contribuir para as discussões acerca da formação de professores de Educação Física por intermédio da educação à distância (EAD), investigando como esta temática tem sido abordada na produção acadêmica no âmbito da Educação Física/Ciências do Esporte para identificar tendências e lacunas na produção do conhecimento. Para tal, o foco das atenções recairá sobre as diferentes abordagens de tematização sobre as relações entre EAD e Educação Física utilizadas nas diferentes produções acadêmicas investigadas.

\section{Procedimentos metodológicos}

Este estudo pode ser caracterizado como uma pesquisa documental alicerçada em um levantamento de dados com base nas produções acadêmicas no âmbito das Ciências do Esporte, que adota como fontes de pesquisa os principais periódicos na área de Educação Física/Ciências do Esporte, os Anais do Congresso Brasileiro de Ciências do Esporte (CONBRACE) a partir do ano de 2005 e o Banco de Teses e Dissertações da CAPES.

A justificativa para o recorte temporal, sobretudo no que diz respeito às produções em anais, é decorrente do fato das produções no $\mathrm{SOAC}^{4}$ do Colégio Brasileiro de Ciências do Esporte estarem disponíveis somente a partir da edição do XIV CONBRACE, realizado no ano de 2005.

No que diz respeito ao Banco de teses e dissertações da Capes, a pesquisa se restringiu às produções realizadas em Programas de Pós-graduação em Educação Física. Levou-se em consideração o fato dos professores de Educação Física eventualmente realizarem seus cursos de Pós-Graduação em outras áreas, com destaque para a educação, entretanto, nosso objeto exigiu o enfoque adotado.

Fez parte do corpus da pesquisa um total de nove periódicos da área de Educação Física. Tal escolha se pautou nos seguintes critérios: a) a disponibilidade de acesso às publicações por meio eletrônico; b) A classificação do periódico no Qualis/Capes 2014 entre A1 e B2; c) Foco e escopo que permitissem a publicação de artigos com enfoque sociocultural e pedagógico. Os periódicos analisados foram: 1) Licere, 2) Revista Brasileira de Ciência e Movimento, 3) Movimento, 4) Pensar a Prática, 5) Educação Física/UEM, 6) Motrivivência, 7) Revista Brasileira de Ciências do Esporte, 8) Motriz, 9) Revista Brasileira de Educação Física e Esporte.

A fim de qualificar o levantamento de dados proposto, foram utilizadas como descritores as expressões "educação à distância" e "EAD", sendo aplicados a todos os escopos de busca.

\section{Apresentação dos dados}

Com base na busca realizada nos nove principais periódicos na área da Educação Física/Ciências do Esporte, foram encontrados os seguintes dados:

\footnotetext{
${ }^{4}$ Sistema Online de Apoio a Congressos. Disponível em:<http://congressos.cbce.org.br/>.
} 
Quadro 1: Número de artigos encontrados por periódico.

\begin{tabular}{|c|c|}
\hline Periódico & $\mathbf{N}$ \\
\hline Educação Física/UEM & 01 \\
\hline Licere & - \\
\hline Motrivivência & 01 \\
\hline Motriz & - \\
\hline Movimento & 01 \\
\hline Pensar a Prática & 02 \\
\hline Revista Brasileira de Ciência e Movimento & 01 \\
\hline Revista Brasileira de Ciências do Esporte (RBCE) & 01 \\
\hline Revista de Educação Física e Esporte & - \\
\hline Total de Artigos encontrados & $\mathbf{0 7}$ \\
\hline
\end{tabular}

Fonte: elaboração dos autores

A partir do quadro pode-se perceber que a temática específica da educação a distância e suas relações com a Educação Física ainda se constitui em um assunto pouco abordado na produção acadêmica da área, sendo que se destaca a Revista Pensar a Prática, com dois artigos publicados, e as Revistas Motrivivência, Educação Física/UEM, Movimento, a Revista Brasileira de Ciência e Movimento e a Revista Brasileira de Ciências do Esporte com uma publicação cada. Nas demais revistas, nenhuma publicação foi encontrada sobre a temática investigada.

O quadro 2 apresenta os autores dos artigos encontrados e também os anos nos quais os mesmos foram publicados:

Quadro 2: Artigos encontrados nos periódicos

\begin{tabular}{|c|c|c|c|}
\hline $\mathbf{N}^{\mathbf{0}}$ & Periódico & Autores & Ano \\
\hline 01 & Revista da Educação Física/UEM & Finck et al & 2002 \\
\hline 02 & Pensar a Prática & Lazzarotti Filho et al & 2013 \\
\hline 03 & Movimento & Quaranta e Pires & 2013 \\
\hline 04 & RBCE & Lazzarotti Filho, Silva e Pires & 2013 \\
\hline 05 & Motrivivência & Lazzarotti Filho et al & 2014 \\
\hline 06 & Pensar a Prática & Lazzarotti Filho et al & 2015 \\
\hline
\end{tabular}

Fonte: elaboração dos autores

Com base na coleta de dados nos periódicos, pode-se afirmar que quase todas as publicações sobre EAD e Educação Física ocorreram entre os anos de 2013 e 2015, indicando que, apesar da formação de professores à distância datar do início dos anos 2000, talvez a especificidade da licenciatura em Educação Física seja mais recente e, consequentemente, a produção sobre o tema. Entretanto, a educação continuada, com destaque para os cursos de especialização à distância, se constitui em uma realidade mais consolidada na área, o que poderia ter resultado em publicações anteriores.

Outro destaque diz respeito ao fato da produção existente sobre o tema investigado parecer concentrar-se nas publicações realizadas por um mesmo grupo de pesquisadores, talvez como resultado de um mesmo projeto de pesquisa.

Outra fonte consultada foi o Banco de Teses da CAPES, visando identificar a produção da pós-graduação brasileira sobre o tema. Nele foram encontradas apenas duas dissertações de mestrado na área de Educação Física que versavam sobre a temática da EAD, respectivamente, os estudos desenvolvidos por Quaranta (2011) e Silva (2012), conforme quadro 3. 
Quadro 3: Produções da pós-graduação disponíveis no Banco deTeses da CAPES ${ }^{5}$

\begin{tabular}{|c|c|c|c|c|}
\hline $\mathbf{N}^{\mathbf{0}}$ & Trabalho acadêmico & Autor & Ano & Instituição \\
\hline 01 & Dissertação & Quaranta & 2011 & UFSC \\
\hline 02 & Dissertação & Silva & 2012 & UNB \\
\hline
\end{tabular}

Fonte: elaboração dos autores

Assim como nos quadros anteriores, é perceptível a escassez de publicações também neste banco de dados, com destaque para o fato de não haver nenhuma tese de doutorado publicada que verse sobre a temática investigada.

A seguir, o quadro 4 apresenta os trabalhos encontrados no âmbito dos Anais do Congresso Brasileiro de Ciências do Esporte:

Quadro 4: Produções nos Anais do CONBRACE ${ }^{6}$

\begin{tabular}{|c|c|c|c|}
\hline $\mathbf{N}^{\mathbf{0}}$ & Evento & Autores & Ano \\
\hline 01 & XVII CONBRACE & Altmann e Martins & 2011 \\
\hline 02 & XVII CONBRACE & Quaranta & 2011 \\
\hline 03 & XVII CONBRACE & Berger et al & 2011 \\
\hline 04 & XVIII CONBRACE & Almeida e Feres Neto & 2013 \\
\hline 05 & XVIII CONBRACE & Machado, Souza e Gemente & 2013 \\
\hline 06 & XVIII CONBRACE & Silva, Gamboa e Silva & 2013 \\
\hline 07 & XIX CONBRACE & Lazzarotti Filho, Pasquali e Furtado & 2015 \\
\hline 08 & XIX CONBRACE & Lazzarotti Filho, Cruvinel e Moraes & 2015 \\
\hline
\end{tabular}

Fonte: elaboração dos autores

No que diz respeito à produção acadêmica no âmbito dos Anais do Congresso Brasileiro de Ciências do Esporte, foram encontrados oito trabalhos. Os mesmos se concentraram nos eventos realizados nos anos de 2011, 2013 e 2015.

Os dados apresentados são coerentes com aqueles apresentados nos quadros anteriores, sobretudo, destacando uma produção escassa e recente sobre as relações entre EAD e Educação Física.

\section{Características da tematização da EAD na produção do campo da Educação Físi- ca/Ciências do Esporte}

Este tópico será dedicado a uma breve descrição das produções encontradas nas três fontes de pesquisa, a fim de elencarmos elementos que nos permitam uma caracterização dos artigos de acordo com as temáticas abordadas para, posteriormente, analisarmos os conteúdos manifestos na presente perspectiva.

\section{a) A produção no âmbito dos periódicos}

Na Revista da Educação Física da UEM, o artigo de Finck et al. (2002) relata a experiência de uma equipe de professores de Educação Física na produção de material para um curso Normal Superior com mídias interativas para professores da educação infantil e séries iniciais. O material contemplou os temas: linguagens, códigos e tecnologias; corpo e movimento e recursos de aprendizagem: jogos vivenciais, didáticos e lúdicos. Para os autores, a

\footnotetext{
${ }^{5}$ Disponível em:<http://bancodeteses.capes.gov.br/>.

${ }^{6}$ Foram encontrados nos Anais do CONBRACE de 2013 dois trabalhos que abordavam a temática da EAD, porém, os mesmos não foram analisados por não atenderem ao outro critério para inclusão, que é a formação de professores.
} 
capacitação desencadeada a partir dessa produção possibilitou aos participantes uma visão crítica e significativa acerca do mundo do movimento e sua importância na formação das crianças.

Com relação à Revista Brasileira de Ciência e Movimento, o estudo de múltiplos casos de Quaranta e Pires (2013) discute a formação de professores de Educação Física na modalidade EAD, tendo como referência os relatos e reflexões dos acadêmicos acerca de suas primeiras experiências docentes no estágio supervisionado. Parte-se das percepções do estágio como momento de fundamental importância para a formação profissional, destacando o papel da experiência docente como fator preponderante no "tornar-se professor". Destaca também limitações sobre a própria estrutura do curso de licenciatura EAD e fragilidades no processo de supervisão do estágio, constatando a ausência de estratégias de acompanhamento presencial por parte da instituição formadora.

No periódico Pensar a prática, Lazzarotti Filho et al. (2015) apresentam um estudo de caso, pautado em análise documental e entrevistas semiestruturadas, compreendendo como um curso de Licenciatura em Educação Física (EAD /UAB/UFG) vem sendo desenvolvido. Destacam que o curso em questão se encontra em fase de consolidação de experiências didático pedagógicas, apresentando como principais limitações a falta de estrutura dos polos, o não domínio das Tecnologias de Informação de Comunicação (TICs) por parte dos cursistas e a intensificação do trabalho docente. Ressaltam, todavia, fatores positivos, como a aquisição de autonomia nos estudos, o letramento digital, a flexibilidade de horários para estudar, a melhoria nos processos de comunicação e a democratização do acesso ao ensino superior.

Neste mesmo periódico, Pimentel et al. (2013) expõem um mapeamento da oferta de cursos de Educação Física na modalidade EAD, identificando as tendências e nuances desta modalidade de formação como estratégia para expansão do ensino superior. Acerca dos dados levantados, foram identificados 28 cursos de educação física a distância, sendo que destes, 24 são oferecidos por Universidades públicas e quatro por outras instituições. Destaca-se que o número de vagas disponibilizadas por essas quatro instituições chega a quase $50 \%$ do total de matrículas considerando os 28 cursos. Os autores também apontam que é necessário o aprofundamento dos estudos acerca da formação profissional em Educação Física na EAD.

O artigo encontrado na Revista Brasileira de Ciências do Esporte, de autoria de Lazzarotti Filho, Silva e Pires (2013), apresenta os resultados de um estudo de caso que visou compreender como é desenvolvido o saber das práticas corporais em um curso de licenciatura em Educação Física na modalidade EAD. Este estudo se pautou em dados coletados em entrevistas semiestruturadas com componentes da equipe pedagógica e, também, análise documental. Conceitualmente, os autores fazem uma distinção entre os saberes da prática corporal e os saberes sobre a prática corporal. E, dessa forma, os resultados apontam que o saber das práticas corporais marca a perspectiva dos componentes da equipe pedagógica, tanto na sua história de vida como em seus processos de escolarização, e é apontada como preocupação para a realização de cursos à distância.

Na Revista Movimento, o artigo de Quaranta e Pires (2013) abordou as influências das histórias de vida na/com a Educação Física na educação básica tomando como base as experiências docentes com estágio supervisionado em um curso de licenciatura em Educação Física na modalidade EAD (UAB/UnB). Os autores levam em consideração algumas limitações de uma modalidade cuja mediação ocorre majoritariamente por meio das TICs em um campo cuja especificidade aponta para a "vivência" das práticas corporais. Os dados da pesquisa apontam que as experiências decorrentes de suas histórias de vida influenciaram mais a escolha das estratégias didáticas dos estagiários, assim como a forma como interpretam suas experiências docentes no estágio.

Na Revista Motrivivência, o estudo de Pimentel et al. (2014) versa sobre a implementação de um curso de Licenciatura em Educação Física na modalidade EAD na UnB no 
contexto do sistema UAB. Os autores indicam que apesar das potencialidades das TICs, o sistema representado para a política do sistema UAB ainda apresenta lacunas e falta de seriedade com o trabalho docente. Também salientam que embora o sistema UAB estabeleça nexos com o ideário neoliberal para a educação, a autonomia das Universidades Federais tem possibilitado uma formação com qualidade crítica e emancipadora, dentre as quais se destaca o curso de Licenciatura investigado.

Com base na análise dos citados artigos é possível apontar as seguintes características na abordagem das temáticas, sintetizadas no quadro 5:

Quadro 5: Temáticas abordadas na produção dos periódicos

\begin{tabular}{|c|c|}
\hline Temáticas abordadas & N \\
\hline Análise da qualidade de curso EAD & $\mathbf{0 2}$ \\
\hline Mapeamento da oferta de cursos de Educação Física na modalidade EAD & $\mathbf{0 1}$ \\
\hline $\begin{array}{c}\text { Desenvolvimento de conteúdo específico em curso de licenciatura em } \\
\text { Educação Física na modalidade EAD }\end{array}$ & $\mathbf{0 1}$ \\
\hline Estágio supervisionado na Educação Física /EAD & $\mathbf{0 2}$ \\
\hline Produção de Material para curso de Educação Física EAD & $\mathbf{0 1}$ \\
\hline Total & $\mathbf{0 7}$ \\
\hline
\end{tabular}

Fonte: elaboração dos autores

\section{b) A produção na pós-graduação disponível no Banco de Teses da CAPES}

A dissertação de Quaranta (2011) foca a formação de professores de Educação Física na modalidade EAD, destacando as experiências de vida dos cursistas e o diálogo com os conteúdos abordados na perspectiva semipresencial, visando à constituição do "tornar-se professor", sobretudo, no contato com a cultura escolar. O curso investigado foi a licenciatura em Educação Física na modalidade à distância oferecida pela Universidade de Brasília (UnB) num determinado polo presencial. Nessa investigação, o autor pesquisou como essa relação ocorria, mediante à análise dos planos de intervenção e dos relatos das práticas de estágios supervisionados de quatro cursistas que não tiveram experiências anteriores com o ensino de Educação Física, que foram entrevistados pelo pesquisador. O autor conclui que as abordagens desenvolvimentistas predominaram nos planos, como uma reprodução de experiências que os cursistas tiveram quando estudantes; houve dificuldade dos estagiários acessarem os Projetos político pedagógicos das escolas, limitando seu diálogo com a cultura escolar; e também foram constatadas deficiências no que diz respeito à supervisão de estágio por parte da Instituição responsável pelo curso.

Já Silva (2012) discute, por meio de um levantamento bibliográfico e análise dos conteúdos de mensagens postadas por professores e cursistas em um Ambiente Virtual de aprendizagem na ferramenta fórum do curso de licenciatura em Educação Física, modalidade EAD, da Universidade Federal de Goiás, elementos como a mediação pedagógica, interação e linguagem, possibilidades midiáticas, uso de tecnologias e a organização das disciplinas. A pesquisa concluiu que o curso investigado, no tocante às categorias mediação e interação dos sujeitos, não conseguiu romper com o velho modelo das escolas de correspondência, fortemente caracterizado pelo baixo diálogo e por poucas possibilidades dos usos de recursos midiáticos e das TICs.

\section{c) A produção nos Anais do Congresso Brasileiro de Ciências do Esporte}

O trabalho de Altman e Martins (2011) problematiza o conceito de corpo apresentado em material específico para um curso de especialização em Educação Física oferecido na mo- 
dalidade EAD no âmbito da rede estadual de ensino de São Paulo. O curso é baseado no currículo da citada rede e apresenta, em seus conteúdos, uma abordagem crítica dos conteúdos da educação física. No presente estudo, os autores advogam em favor de uma abordagem crítica acerca do tema "corpo".

Com relação ao trabalho de Quaranta (2011), o autor apresenta um relato sobre um estudo então em andamento, tratando da interpretação das experiências docentes de estagiários de um curso de licenciatura em Educação Física na modalidade EAD sobre suas intervenções durante o estágio supervisionado. A pesquisa se pautou em um estudo de múltiplos casos com base na descrição interpretativa dos planos de ensino de quatro cursistas, sem qualquer experiência docente anterior, além de entrevistas com os mesmos visando compreender suas experiências docentes.

Acerca do estudo de Berger et al. (2011), os autores apresentam um relato sobre o desenvolvimento de uma proposta de formação continuada para professores, realizada na modalidade EAD, desenvolvida pelo Centro de Artes e Educação Física da UFRGS. Segundo os autores, a experiência bem sucedida do curso resultou em uma parceria com o MEC por meio do Plano de ações articuladas, atendendo cerca de 3.800 professores em dois anos, em 11 estados da Federação.

A investigação de Almeida e Feres Neto (2013) abordou como o conhecimento próprio das disciplinas teórico-metodológicas de um curso de licenciatura em Educação Física (EAD) é mediado pelos professores, pautando-se nos aspectos metodológicos específicos do curso e na apropriação dos conhecimentos por parte dos acadêmicos nessas disciplinas. Segundo os autores, é possível inferir que ocorre um aligeiramento e a virtualização dos saberes próprios das disciplinas práticas do curso de Educação Física, em sua modalidade on-line, fenômeno este que influencia uma ressignificação tanto dos conhecimentos quanto das mediações pedagógicas utilizadas em tais cursos.

O trabalho de Machado, Souza e Gemente (2013), partindo da hipótese de uma suposta dificuldade em garantir a qualidade dos cursos de Educação Física na esfera da EAD, cujas disciplinas, em parte, carecem de envolvimento prático, visa apresentar uma experiência bem sucedida com a disciplina de atletismo. Os autores apontam a necessidade de complementação das atividades realizadas no ambiente virtual de aprendizagem com aulas presenciais que possibilitem um mínimo de "vivências práticas" dos conteúdos.

A pesquisa de Silva, Gamboa e Silva (2013) teve como meta identificar e analisar as teorias educacionais e os pressupostos político-filosóficos que embasam o projeto pedagógico dos cursos de formação continuada oferecidos pela Escola de Formação e Aperfeiçoamento de Professores (EFAP) da Rede Estadual de Ensino do Estado de São Paulo (REE/SP), no período de 2009 a 2012. Com relação à formação dos professores de Educação Física, inferese que as políticas de formação dos quadros docentes do Estado de São Paulo foram e continuam inadequadas, pois os programas de formação continuada oferecidos são realizados na modalidade EAD, privilegiando as tele e videoconferências, bem como porque as propostas desses programas não atendem às reais demandas dos profissionais da Educação/Educação Física, tampouco consideram a formação do sujeito e, sim, a intensificação de modelos preestabelecidos.

No que tange ao estudo de Lazzarotti Filho, Pasquali e Furtado (2015), discute-se a formação de professores em um curso de Educação Física na modalidade EAD, tomando como base o perfil sociodemográfico dos egressos, assim como o que ficou de significativo do curso para os mesmos. Os autores concluem que o letramento digital foi a principal contribuição para os cursistas, somado à interação entre os saberes pedagógicos desenvolvidos no curso e os saberes das práticas corporais e a compreensão da importância da Educação Física no processo de escolarização. 
Finalizando os achados, o trabalho de Lazzarotti Filho, Cruvinel e Moraes (2015) investiga o papel e ação do tutor à distância no curso de licenciatura em Educação Física $\mathrm{EAD} / \mathrm{UAB} / \mathrm{UnB}$ identificando as principais problemáticas deste profissional neste contexto. Para os autores, há uma contradição estabelecida entre a boa qualificação e a responsabilidade que é exigida dos tutores neste curso para garantir uma formação de qualidade, e o seu não reconhecimento financeiro e acadêmico, culminando na precarização do trabalho docente.

Com base na análise dos trabalhos anteriormente apresentados é possível apontar as seguintes características na abordagem das temáticas, sintetizadas no quadro 6:

Quadro 6: Temáticas abordadas na produção veiculada no CONBRACE

\begin{tabular}{|c|c|}
\hline Temáticas abordadas & N \\
\hline Formação em Educação Física na EAD & 02 \\
\hline Análise de fundamentação teórica de curso EAD & 01 \\
\hline Análise de tema específico da Educação Física na EAD & 01 \\
\hline Docência na EAD & 01 \\
\hline $\begin{array}{c}\text { Desenvolvimento de conteúdo específico em curso de licenciatura em } \\
\text { Educação Física na modalidade EAD }\end{array}$ & 01 \\
\hline Estágio supervisionado na Educação Física /EAD & 01 \\
\hline Produção de Material para curso de Educação Física EAD & 01 \\
\hline Total & $\mathbf{0 8}$ \\
\hline
\end{tabular}

Fonte: elaboração dos autores

\section{Discussão dos resultados}

Com base nos dados coletados nas diferentes produções acadêmicas no âmbito da área de Educação Física/Ciências do Esporte é possível afirmar que a temática da Educação a distância e suas relações com a citada área ainda se constitui em um campo a ser explorado. Isto porque o levantamento proposto, que tomou como base as produções localizadas nos principais periódicos da área, no banco de Teses da Capes e nos Anais do CONBRACE a partir do ano de 1997, foi finalizado com apenas 18 achados. Tal fato confirma os dados do estudo proposto por Lisboa e Pires (2013) ${ }^{7}$. De acordo com os autores, verificou-se. nos últimos anos. a ampliação da oferta de cursos de formação de professores de Educação Física na modalidade EaD, contudo,

tal situação, longe de propiciar o aumento do debate/reflexão sobre características, competências, e identidade profissional do professor de Educação Física, para que a qualidade e especificidades da formação inicial sejam garantidas à luz (também) das mudanças propiciadas pelas TICs e inovações educacionais, tem se configurado muito mais como um vazio e lacuna dessa área (2013, p.61-62).

Também, ilustra esse panorama de escassa produção os dados do estudo de Pimentel et al. (2013), que mapeou 28 cursos de Educação Física na modalidade EAD que, por alguma razão, não foram investigados até o momento, o que nos limita uma análise mais abrangente face a esta miríade de cursos. E, dada a repetição de alguns autores no conjunto das publicações identificadas e analisadas, percebe-se que são poucos os pesquisadores da área que tem se dedicado a investigar a formação de professores de Educação Física na EAD.

\footnotetext{
${ }^{7}$ Embora aborde os cursos de licenciatura em Educação Física na modalidade EAD, esse texto não foi analisado nessa pesquisa por ter sido publicado em periódico da Educação. Aliás, é possível que esse fato se repita em outros periódicos do campo da Educação, inclusive específicos da Educação a distância, o que mereceria uma outra investigação.
} 
No que tange aos trabalhos encontrados, é possível destacar um volume de produções concentrados entre os anos de 2011 e 2015, revelando, assim, o caráter recente que esta temática tem assumido na área da Educação Física. Também, cabe destacar a recorrência de publicações por um mesmo pesquisador ou grupo de pesquisadores sobre dois cursos de licenciatura em Educação Física na modalidade EAD: o da UnB e o da UFG. No caso do primeiro, este foi o pioneiro na oferta e, com relação ao segundo, foi o primeiro que instituiu o curso EAD como permanente. Talvez decorra daí o fato de serem os cursos mais investigados.

Outro dado interessante identificado na pesquisa diz respeito ao fato de um dos autores identificados aparecer nas três fontes consultadas (Periódicos, Banco de Teses e CONBRA$\mathrm{CE}$ ). Isso talvez reflita o seu percurso investigativo, com um estudo em desenvolvimento publicado nos anais de um evento, a dissertação defendida, presente no Banco de Teses e a consequentemente publicação de seus achados de pesquisa em periódicos da área, indicando um ciclo virtuoso de produção/socialização da pesquisa.

Também é importante mencionar o fato de um dos autores com publicações em periódicos e nos Anais do CONBRACE, ter o foco de seus estudos voltados para o curso de Licenciatura em Educação Física na modalidade EAD desenvolvido em sua própria instituição, o que parece indicar uma preocupação com a qualidade do curso e a contribuição para o seu aperfeiçoamento a partir dos apontamentos da pesquisa.

No que diz respeito às características das temáticas abordadas nas produções encontradas, pode-se afirmar que os estudos realizados destacam importantes questões referentes à EAD e suas relações com a Educação Física, com especial destaque para a formação inicial, mas, também, abrangendo estudos sobre a formação continuada. Isto porque, segundo Ripa (2015), trata-se de uma modalidade que tem sido utilizada pelas políticas públicas para acelerar a expansão e interiorização do ensino superior no contexto brasileiro e fomentar a formação inicial e continuada de professores.

Pode-se destacar a análise da qualidade da formação proporcionada por cursos de licenciatura em Educação Física na modalidade EAD como um tema recorrente nas pesquisas. Nessa perspectiva, estão presentes análises de fundamentação teórica dos cursos, além da discussão sobre temas específicos da Educação Física neste âmbito e também o desenvolvimento de conteúdos (disciplinas) da área nesses cursos, em que assumem papel fundamental as mediações realizadas pelos formadores. Com relação às mediações, de acordo com Belloni, (2003, p. 54) no processo de formação EAD, "a interação entre o professor e o estudante ocorre de modo indireto no espaço (a distância, descontínua) e no tempo (comunicação diferida, não simultânea), o que acrescenta complexidade ao já bastante complexo processo de ensino e aprendizagem na EaD”.

Dessa maneira, percebe-se o quanto esta modalidade de ensino que tem englobado a formação inicial em Educação Física tem implicado em estudos que verifiquem como se dá o trato com os conhecimentos específicos da área, expondo, talvez, preocupações com o caráter recente dessa modalidade e certas desconfianças no que tange a constituição da identidade profissional. Conforme Lazzarotti Filho, Silva e Pires (2013, p.703),

na EaD, faz-se necessário investigar como os saberes das práticas corporais vem sendo desenvolvidos, visto que essa nova formação incorpora a mediação por computadores e em espaço virtual, assumindo contornos diferenciados daquilo que tradicionalmente vinha sendo realizado no campo, mediação essa que pode estar acirrando as contradições e ambiguidades do campo no que tange a sua tradição com os saberes das práticas corporais.

Assume destaque nas temáticas a questão da produção de materiais para cursos EAD e o desenvolvimento de conteúdos específicos para a Licenciatura em Educação Física. Esta também se constitui em uma temática atrelada à preocupação com a formação oferecida nes- 
ses cursos, nos quais compreender como os cursistas apreendem e interagem com os materiais disponíveis nos ambientes virtuais de aprendizagem também adquire destacada relevância. Isto porque o letramento digital e o acesso e produção de conhecimentos por meio das tecnologias se constitui em uma das bases dessa modalidade de ensino, implicando numa dimensão processual, mas também apriorística na relação com os conhecimentos da área. Neste sentido, a valoração positiva do letramento digital "é uma possibilidade de superação do problema da falta de domínio das TIC, por meio da apropriação das ferramentas digitais para dinamizar o processo ensino-aprendizagem, promovendo interação, mediação e apropriação de conhecimentos" (CRUVINEL et al, 2015, p.11) ${ }^{8}$.

Outro ponto fundamental que constituiu as temáticas encontradas diz respeito especificamente ao estágio supervisionado em Educação Física na modalidade EAD, em que se percebem, com base nas produções, algumas limitações para o desenvolvimento das propostas pedagógicas dos estagiários, dadas as características da mediação e acompanhamento do estágio nessa modalidade de ensino. Também suscitam problemas com relação ao próprio contato dos estagiários com a cultura escolar, PPPs das escolas e a constituição de seu fazer docente, que acaba em muitas vezes tomando como base suas experiências como escolares ou mesmo os modelos de aulas de seus professores de Educação Física escolar. De acordo com Quaranta (2011), a falta de um processo de supervisão adequada revela-se como um fator limitador da formação, pela ausência de um interlocutor que propicie reflexões pautadas nas especificidades pedagógicas da área.

\section{Considerações finais}

Levando em consideração a proposta do presente estudo de apresentar um balanço da produção acadêmica sobre EAD no âmbito das Ciências do Esporte, é possível afirmar que a produção identificada é reveladora de aspectos bastante específicos no que tange tanto à formação inicial quanto continuada de professores. Há uma clara preocupação com a qualidade dos cursos, conteúdos, dinâmicas propostas, o estágio supervisionado e os conhecimentos considerados centrais na formação e constituição da identidade profissional da área. Tais preocupações inferem que a formação de professores na modalidade EAD ainda precisa apresentar algumas respostas no que tange aos aspectos formativos que extrapolam os limites da transmissão de conhecimentos (que pode ser potencializada pelas TDICs). Ou seja, há que se considerar o contato com a cultura escolar, a formação política do docente, o acompanhamento do estágio, entre outros aspectos cujo caráter presencial formativo ainda parece ser fundamental.

Pode-se indicar como lacunas na produção dos conhecimentos investigações com egressos dos cursos visando acompanhar os êxitos e limitações desta formação na modalidade EAD e suas implicações para a atuação docente. Estudos sobre a questão do letramento digital e a própria utilização das tecnologias como elementos estruturantes da prática pedagógica também são necessários, visando uma formação para, com e através das tecnologias, numa perspectiva mídia-educativa (FANTIN, 2006). Isto porque, a formação de professores pela EAD integra as Tecnologias de Informação e Comunicação e se pauta na autonomia do estudante e, assim sendo, o professor deve conhecer e dominar tais tecnologias, como usuário competente, crítico e criativo, estando mais apto para ensinar com elas (LAPA; BELLONI, 2012).

\footnotetext{
${ }^{8}$ Nesta perspectiva, é importante citar o Curso de Especialização "Educação na Cultura Digital” que está sendo desenvolvido na modalidade EAD numa parceria entre o MEC e a UFSC e que conta com um núcleo específico de Educação Física, cujo objetivo é proporcionar aos professores um aprofundamento teórico sobre as práticas corporais presentes na escola e seus possíveis atravessamentos pelas Tecnologias Digitais de Informação e Comunicação. Disponível em:< http://educacaonaculturadigital.mec.gov.br/>.
} 
Outro tema interessante para investigações futuras seria compreender como uma formação acadêmica/profissional em uma área pautada no movimento humano, entendido como uma forma de diálogo do homem com/no mundo, pode se dar plenamente sendo que os acadêmicos desenvolvem as diversas linguagens/possibilidades corporais sem estarem disponíveis corporalmente na EAD (LISBOA; PIRES, 2013).

Torna-se necessário também propor alternativas às práticas tradicionais de $\mathrm{EAD}$ nos cursos de formação de professores, nos quais a autoaprendizagem dos cursistas é pautada em um contato solitário com os materiais do curso, as atividades propostas e os feedbacks pontuais de tutores, sendo marcada pela instrução unidirecional e caracterizando uma "educação distante" (ZUIN, 2006). E, no caso específico da formação de professores que adotam como objeto de estudo e intervenção o movimento humano, o "presencial" como expressão dos momentos de experiências como docente em formação, precisa ser considerado na formulação dos cursos, propostas de atividades e acompanhamento dos graduandos, sob pena de se tornar uma modalidade de formação desacreditada e vista preconceituosamente no meio acadêmico/profissional.

Face ao exposto e tomando como base a pouca produção sobre esta temática específica, pode-se afirmar que a mesma ainda se constitui em um campo a ser explorado pelos pesquisadores na área da Educação Física. Dessa forma, almeja-se que este trabalho possa contribuir para o campo acadêmico, fornecendo um possível estado atual das produções acadêmicas referentes às relações entre Educação Física e EAD, indicando limitações e possibilidades de investigações e abrindo caminho para novos estudos que contribuam para o aprofundamento das reflexões acerca da formação de professores da área na modalidade EAD.

\title{
PHYSICAL EDUCATION, TEACHER TRAINING AND DISTANCE EDUCATION (DE): INVESTIGATING THE KNOWLEDGE PRODUCTION IN THE SPORT SCI- ENCE'S FIELD
}

\begin{abstract}
The aim of this research is to contribute to the discussions about the Physical Education teacher training through distance education (DE) by identifying how the subject is being approached in the main academic productions of the area. To this end, it presents a survey based on the main journals in the field of Physical Education/Sport Sciences, the Banco de Teses e Dissertações from CAPES and the Brazilian Congress of Sport Sciences Proceedings. Based on identification of specific themes related to DE, it is presented a possible "state of the art" on the topic investigated, as well as gaps to be filled by future studies that focus on the relations between physical education and distance education.

Keywords: Physical Education. Teacher Training. Distance Education.

\section{EDUCACIÓN FÍSICA, FORMACIÓN DEL PROFESORADO Y EDUCACIÓN A DISTANCIA (EAD): INVESTIGANDO LA PRODUCCIÓN DEL CONOCIMIENTO EN EL ÁMBITO DE LAS CIENCIAS DEL DEPORTE}

\section{Resumen}

El objetivo de esta investigación es contribuir con las discusiones acerca de la formación de profesores de Educación Física en la modalidad a distancia (EAD), identificando de qué forma el tema está siendo tratado en las principales producciones académicas del área. Con este fin, se presenta un estudio basado en las principales revistas del campo de la Educación Física / Ciencias del Deporte, el Banco de disertaciones y tesis de la Capes y los en Anales del Congreso Brasileño de Ciencias del Deporte. A partir de la identificación de cuestiones específi- 
cas relacionadas con la EAD. Y, presentado un posible "estado del arte" sobre el tema investigado, así como las lagunas a ser ocupadas por los futuros estudios que se centran en las relaciones entre la Educación Eísica y la EAD.

Palabras-clave: Educación Física. Formación del Profesorado. Educación a Distancia.

\section{Referências}

ALMEIDA, G. C. F. de; FERES NETO, A. As mediações pedagógicas na formação docente à distância em educação física: uma análise das disciplinas que tratam das práticas corporais. In: Congresso Brasileiro de Ciências do Esporte, 18. Brasília. Anais..., Brasília: Conbrace, 2013.

ALTMANN, H.; MARTINS, C. J.“educação do corpo" como conteúdo de um curso de educação à distância. In: Congresso Brasileiro de Ciências do Esporte, 17. Porto Alegre. Anais..., Porto Alegre: Conbrace, 2011.

ARRUDA, E. P.; ARRUDA, D. E. P. Educação à distância no Brasil: políticas públicas e democratização do acesso ao ensino superior. Educação em Revista, Belo Horizonte, v. 31, n.3, p. 321-338, 2015.

BELLONI, M. L. Educação a distância, 3. ed. Campinas: Autores Associados, 2003.

BERGER, S. B; et al. A formação continuada de professores de educação física através da educação a distância: o CAEF da UFRGS no plano de ações articuladas do seb/mec. In: Congresso Brasileiro de Ciências do Esporte, 17. Porto Alegre. Anais..., Porto Alegre: Conbrace, 2011.

BRASIL. Lei n ${ }^{\circ}$ 9.394, de 20 de dezembro de 1996. Estabelece as diretrizes e bases da educação nacional. Diário Oficial da União, Brasília, 23 dez. 1996. Disponível em: <http://www.planalto.gov.br/ccivil_03/Leis/L9394.htm>. Acesso em: 20 ago. 2011

BRASIL. Lei $\mathrm{n}^{\circ}$ 10.172, de 9 de janeiro de 2001. Aprova o Plano Nacional de Educação e dá outras providências. Diário Oficial da União, Brasília. Disponível em:< http://www.planalto.gov.br/ccivil_03/leis/leis_2001/110172.htm>. Acesso em: 10 jan. 2001.

BRASIL. Fórum das Estatais pela Educação.Projeto: Universidade Aberta do Brasil, 2005. Disponível em: <portal.mec.gov.br/arquivos/pdf/universidade.pdf>. Acesso em: 21 out. 2012.

FANTIN, M. Mídia-Educação: conceitos, experiências, diálogos Brasil-Itália. Florianópolis: Cidade Futura, 2006.

FINCK, S. C. M.; et al. Intervenção/ação: contribuições da educação física no curso normal superior com mídias interativas. Revista da Educação Física/UEM, Maringá, v. 13, n. 2 p. 151-155, 2002.

LAPA, A. B.; BELLONI, M. L. Educação a distância como mídia-educação. Perspectiva, Florianópolis, v. 30, n.1, p.175-196, , 2012. 
LAZZAROTTI FILHO, A.; et al. Expansão do ensino superior e formação profissional em educação física: um mapeamento dos cursos na modalidade de educação a distância. Pensar a Prática, Goiânia, v. 16, n. 4, p. 956-1270, 2013.

LAZZAROTTI FILHO, A.; et al. A dinâmica, os principais problemas e as qualidades no desenvolvimento de um curso de licenciatura em educação física na modalidade a distância. Pensar a Prática, Goiânia, v. 18, n. 3, 2015.

LAZZAROTTI FILHO, A.; PIRES, G. de L.; SILVA, A. M. Saberes e práticas corporais na formação de professores de educação física na modalidade a distância. Revista Brasileira de Ciências do Esporte, Florianópolis, v. 35, n. 3, p. 701-715, 2013.

LAZZAROTTI FILHO, A.; et al. formação de professores de educação física a distância: a experiência da Universidade de Brasília. Motrivivência. v. 26, n. 43, p. 55-69, 2014.

LAZZAROTTI FILHO; PASQUALI; FURTADO. Quem ficou e o que ficou na formação do curso de educação física, licenciatura, na modalidade a distância. Congresso Brasileiro de Ciências do Esporte, 19. Vitória. Anais..., Vitória: Conbrace, 2015.

LAZZAROTTI FILHO, A.; CRUVINEL, F.; MORAES, R. de A. Política de expansão do ensino superior através da modalidade a distância: o papel do tutor no curso de licenciatura em educação física. In: Congresso Brasileiro de Ciências do Esporte, 19. Vitória. Anais..., Vitória, Conbrace, 2015.

LISBOA, M. M.; PIRES, G. D. L. Tecnologias e a formação inicial do professor de educação física: reflexões sobre a educação a distância. Atos de pesquisa em educação, v. 8, n. 1, p. 60-81, 2013.

MACHADO, G. M.; SOUZA, R. O. de; GEMENTE, F. R. F. Pesquisa e ensino em atletismo na modalidade a distância. In: Congresso Brasileiro de Ciências do Esporte, 18. Brasília. Anais..., Brasília: Conbrace, 2013.

QUARANTA, A. M. O estágio supervisionado na formação de professores de educação física à distância sob o olhar da cultura escolar. In: Congresso Brasileiro de Ciências do Esporte, 17. Porto Alegre. Anais..., Porto Alegre: Conbrace, 2011.

QUARANTA, A. M. Formação de professores de educação física na modalidade de educação à distância: experiências docentes no estágio supervisionado. 2011. 207 f. Dissertação (Mestrado em Educação Física) - Universidade Federal de Santa Catarina, 2011.

QUARANTA, A. M.; PIRES, G. de L. Histórias de vida e experiências docentes no estágio supervisionado de licenciandos em Educação Física - modalidade EaD. Movimento. Porto Alegre, v. 19, n. 02, p. 185-205, 2013.

QUARANTA A.M.; PIRES G.D.L. Formação de professores de Educação Física na EAD: inserção na cultura escolar através do estágio supervisionado. Revista brasileira Ciência e Movimento, v. 21, n. 1, p.51-65, 2013.

RIPA, R. Reflexões sobre o "ser professor" na Ead: estamos diante de uma descaracterização do trabalho docente? Comunicações. Piracicaba, n. 3, p. 75-85, 2015. 
SILVA, M. Z. da. A mediação pedagógica no ambiente virtual de aprendizagem: Análise dos fóruns do curso a distancia de Educação Física. 2012. 97 f. Dissertação (Mestrado em Educação Física). Universidade de Brasília, 2012.

SILVA, S. M. F. M; GAMBOA, S. A. S.; SILVA, R. H. dos R. Formação de professores de educação física do estado de São Paulo: a EFAP em debate. In: Congresso Brasileiro de Ciências do Esporte, 18. Brasília. Anais..., Brasília: Conbrace, 2013.

ZUIN, A. A. S. Educação à distância ou educação distante: o programa Universidade Aberta do Brasil, o tutor e o professor virtual. Educação e Sociedade. Campinas, vol. 27, n. 96 p. 935-954, 2006.

Recebido em: 05/05/2016

Revisado em: 24/05/2016

Aprovado em: 22/07/2016

Endereço para correspondência:

juliano_silveira@yahoo.com.br

Juliano Silveira

Universidade Federal de Santa Catarina, Centro de Desportos

Rua Deputado Antônio Edu Vieira, s/n

Pantanal

88036-020 - Florianópolis, SC - Brasil 